RESEARCH REPORT

\title{
Physical functioning in elderly Europeans: 10 year changes in the north and south: the HALE project
}

\author{
Sinikka Äijänseppä, Irma-Leena Notkola, Marja Tijhuis, Wija van Staveren, Daan Kromhout, \\ Aulikki Nissinen
}

J Epidemiol Community Health 2005;59:413-419. doi: 10.1136/jech.2004.026302

See end of article for authors' affiliations

.....................

Correspondence to: Dr S Äijänseppä, National Public Health Institute, Mannerheimintie 166, Helsinki, Finland; sinikka. aijanseppa@ktl.fi

Accepted for publication 17 November 2004

\begin{abstract}
Objectives: To examine age related changes in physical functioning in elderly men and women. Design: Prospective, population based study.

Setting: Population of 15 rural and urban centres in 10 European countries.

Participants: Altogether 3496 men and women born between 1900 and 1920 who participated in the baseline survey of the HALE project in 1988-1991. The study population was examined again about five (in 1993-1995) and 10 (in 1999-2001) years after the baseline examination.

Main outcome measures: Physical functioning was measured by means of a self administered questionnaire of activities of daily living (ADL). Dichotomised prevalence of disability and need for help in self care and mobility ADL were used as dependent variables in the analyses.

Results: Prevalence of disability and need for help tended to be higher in women than in men and in mobility abilities than in self care activities. Disability and need for help increased with advancing age but ameliorated over time from one birth cohort to another. In longitudinal analyses this beneficial time trend was independent of the effect of age, study, and region in self care disability in men and women (OR 0.85, $95 \% \mathrm{Cl} 0.75$ to 0.97 and OR $0.64,95 \% \mathrm{Cl} 0.43$ to 0.97 , respectively) and self care need for help in men (OR $0.83,95 \% \mathrm{Cl} 0.70$ to 0.96 ). Mobility disability among men and self care disability among women decreased more in the south than in the north.

Conclusion: While European populations are aging, the proportions of elderly people with disability are decreasing. These results suggest that dynamics of functioning may differ across cultures. Future studies are needed to clarify which potentially modifiable and culturally determined factors protect against functional decline.
\end{abstract}


from a random age and sex stratified sample of inhabitants from 15 European towns. Subjects living in psychogeriatric nursing homes were excluded. At baseline in 1988 men and women born between 1913 and 1918 were invited to the study. Follow up surveys were performed in 1993 and 1999. In this study five of the 15 centres were excluded because only baseline data were available from them.

Around 3500 men and women examined in 1988-91 in the context of FINE and SENECA studies are included in the HALE database. The general objective of the HALE project is to study cultural differences and changes in and determinants of physical, psychological, social, and cognitive aspects of health and functioning in elderly Europeans. To enable cross cultural comparison the study population was dichotomised into north and south based on dietary and health related lifestyle factors. Figure 1 shows how this study population ( $\mathrm{n}=3496$ at baseline) was formed, study centres by region and study, numbers of subjects per study, numbers of deceased between examination years, participation rates, and activities of daily living (ADL) participation rates.

The initial participation rate in the FINE study was quite high $(76.3 \%)$ but in the SENECA study less than $50 \%$ of men and women initially invited to the participated in the baseline examinations. In both regions, north and south, participation rates varied from about $40 \%$ to $60 \%$ between centres.

\section{Measurements}

Physical functioning was measured by self administered questionnaires on capacity to perform ADL. These questionnaires are adapted from a standardised World Health Organisation questionnaire. ${ }^{14}$ Twelve items identical in the 17 item version used in SENECA and the 14 item version used in FINE were included in the HALE database.

The level of competence in each of these items was measured on a four point scale: (1) able to do without difficulty, (2) able to do with difficulty but without help, (3) able to do only with help, (4) unable to complete. For the purpose of this study, two ability scores were calculated: self care ADL and mobility ADL (see appendix 1 for details). Initially, a sum score of instrumental ADL that consisted of two items concerning light and heavy housework was also determined but it was excluded from further analyses as irrelevant for elderly men.

For the purpose of this study the sum scores in both domains (self care and mobility abilities) were dichotomised into two outcome variables: disability (difficulty) in performing one or more of the items constituting the sum score (coded as 1) compared with no disability in any of the items (coded as 0 ) and need for help in one or more of the items (coded as 1) compared with no help needed (coded as 0 ) in performing these activities. Disability in performing a task

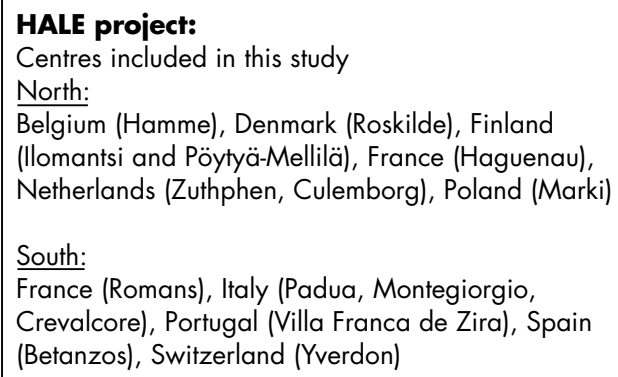

\section{FINE}

Finland, Netherlands (Zutphen), Italy: Montegiorgio and Crevalcore.

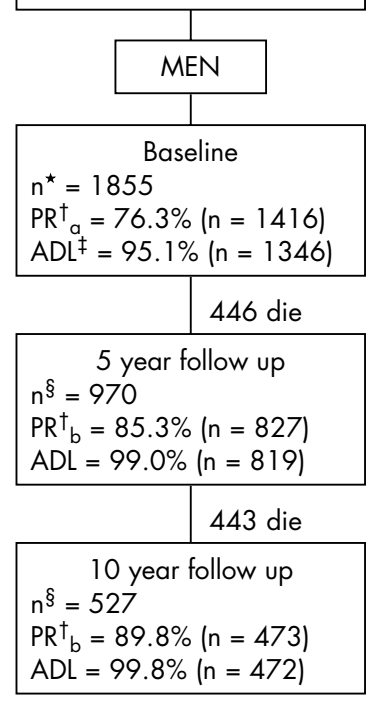

\section{SENECA}

Belgium, Denmark, France, Italy (Padua), Netherlands (Culemborg), Poland, Portugal, Spain, Switzerland

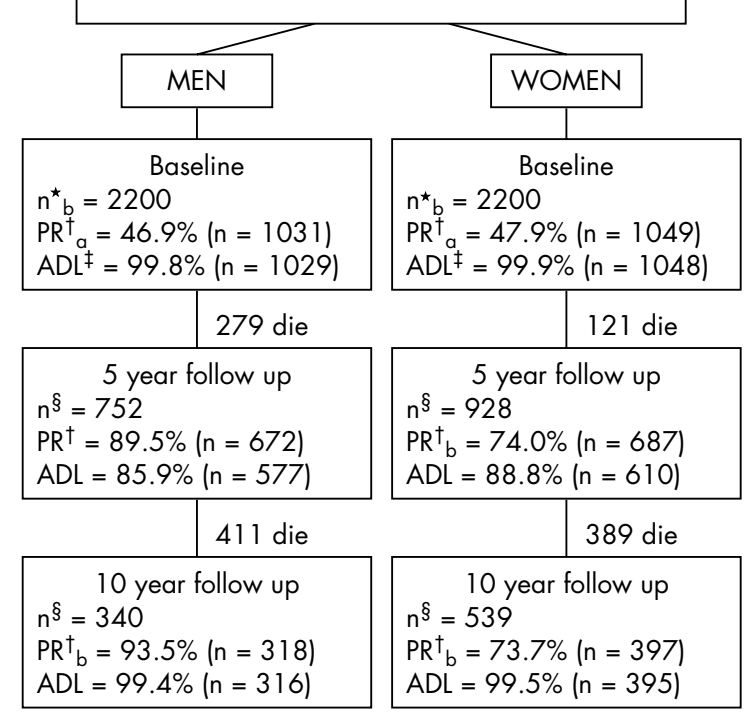

Figure 1 Formation of the study population. * $n=(a)$ Total number of survivors in the original study cohorts; (b) total number of persons invited to the study. $+P R=$ (a) participation rate at baseline (number of participants $/ n^{*}{ }_{a}$ or $n^{*} b$ ); (b) participation rate at follow up (number of participants/ $\left.n \S\right)$. $\ddagger \mathrm{ADL}=\%$ (number) of completed $\mathrm{ADL}$ questionnaires. $\delta \mathrm{n}=$ number of survivors among baseline participants. 
Table 1 Baseline characteristics of the study population by region

\begin{tabular}{llll}
\hline Characteristic & $\begin{array}{l}\text { North } \\
\left(\mathbf{n}=1951^{*}\right)\end{array}$ & $\begin{array}{l}\text { South } \\
\left(\mathbf{n}=1538^{*}\right)\end{array}$ & p Value \\
\hline Age at baseline, years (SD) & $74.4(4.1)$ & $73.6(3.4)$ & $<0.001$ \\
Years of education, years (SD) & $8.2(4.1)$ & $6.7(4.1)$ & $<0.001$ \\
Women, \% (n) & $23.7(463)$ & $38.1(586)$ & $<0.001$ \\
Relative healtht, \%(n) & $90.8(727)$ & $88.7(996)$ & 0.151 \\
Relative activityt,\%(n) & $80.9(1579)$ & $79.8(1228)$ & 0.439 \\
Living alone, \%(n) & $23.8(454)$ & $21.3(326)$ & 0.078 \\
Married/living with partner, \%(n) & $65.8(1283)$ & $63.1(971)$ & 0.109 \\
\hline
\end{tabular}

*Total number at baseline. TProportion of subjects rating their health/physical activity as good as or better than others of same age. Figures are means (SD) or \% (number of respondents).

can be regarded as subjective experience of coping whereas need for help is an indicator of outside assistance needed, whether provided by the healthcare system or family members. Based on the hierarchical order of the three ADL domains ${ }^{15}$ it is justifiable to conclude that disability or need for help in self care abilities in this population is indicative of moderately severe or possibly even severe functional impairment.

In this study, FINE and SENECA study populations were first analysed separately. However, as the differences between the two databases with respect to disability and need for help prevalences and magnitude of changes were small and statistically not significant, the final analyses were performed for the study population as a whole. As the Netherlands had a centre in both FINE and SENECA study we ran sub-analyses in Dutch data to check comparability of the ADL questionnaires between the two studies. We found no significant differences in prevalence levels or magnitude of changes between the two Dutch centres.

\section{Statistical methods}

The presence of functional disability and need for help at the three examination points are described by age specific prevalence rates calculated separately for men and women by region. The $\chi^{2}$ test was used to test the differences between age groups and the two regions.

In modelling the data, all cross sectional measurements for the study persons were included, and logistic generalised estimating equation (GEE) models that take into account the dependence between repeated measurements within the same person were used, by the XTGEE procedure of Stata 7.0. ${ }^{16}$ Separate models were fitted for dichotomised disability and need for help in self care and mobility, separately for men, women, and both sexes. The dichotomised outcome variables were used because the outcome measures were not normally distributed. Follow up period, age (years) as two terms (age and $\left.\operatorname{age}^{2}\right)$, study $(1=$ SENECA, $2=$ FINE $)$ and region $(1=$ north, $2=$ south) were entered into the models as covariates. In the models for both sexes only SENECA data were included, to ensure the comparability of the data; as mentioned above, women were not included in the FINE study.

The data were analysed with statistical packages SPSS (version 11.5 for Windows) and Stata (version 7.0). p Values below 0.05 were regarded as significant. Two tailed tests were used when appropriate.

\section{RESULTS}

Of the total study population 59\% lived in northern and $41 \%$ in southern Europe. The average age and educational level were higher in the north than in the south (table 1). Subjects in the north rated their health and physical activity slightly better in relation to others of same age. No significant regional differences were found with respect to living or marital status.

Tables 2A and 2B show, respectively, the prevalences of disability and need for help in the two domains by age group and region. Throughout the follow up, both sexes reported higher prevalence of disability than that of need for help in all age groups in both regions. In both domains disability and need for help increased towards higher age groups in all study years. In mobility activities the prevalence of disability varied from one third in the youngest up to $100 \%$ in the highest age groups but help was needed by roughly one half of those reporting disability. Disability and need for help in self care abilities was less common than in mobility abilities. During the follow up disability and need for help increased with age in all baseline age groups in both domains and both sexes.

Table 2 (A) Disability in self care and mobility abilities per age group in men and women in north and south of Europe

\begin{tabular}{|c|c|c|c|c|c|c|c|c|c|c|c|c|c|}
\hline & \multirow{4}{*}{$\begin{array}{l}\text { Age } \\
\text { group }\end{array}$} & \multicolumn{12}{|c|}{ Prevalence of disability } \\
\hline & & \multicolumn{6}{|l|}{ Men } & \multicolumn{6}{|l|}{ Women } \\
\hline & & \multicolumn{3}{|l|}{ Self care } & \multicolumn{3}{|l|}{ Mobility } & \multicolumn{3}{|l|}{ Self care } & \multicolumn{3}{|l|}{ Mobility } \\
\hline & & 1988-1991 & 1993-1995 & $1998-2000$ & $1988-1991$ & 1993-1995 & $1998-2000$ & 1988-1991 & 1993-1995 & $1998-2000$ & 1988-1991 & 1993-1995 & $1998-2000$ \\
\hline & & $*$ & ** & ** & $* *$ & ** & ** & NS & NS & * & NS & NS & NS \\
\hline \multirow{6}{*}{ North } & $70-74$ & $12.7(102)$ & - & - & $32.4(261)$ & - & - & $14.7(57)$ & - & - & $61.0(236)$ & - & - \\
\hline & $75-79$ & $22.4(89)$ & $15.2(78)$ & - & $40.3(159)$ & $44.2(227)$ & - & 27.4 (17) & $21.2(47)$ & - & $61.8(47)$ & $68.9(153)$ & - \\
\hline & $80-84$ & $29.9(50)$ & $22.4(47)$ & $25.5(66)$ & $52.7(88)$ & $50.0(105)$ & $52.5(136)$ & - & $32.4(11)$ & $40.9(45)$ & - & $82.4(28)$ & $83.6(92)$ \\
\hline & $85-89$ & $38.3(23)$ & $33.7(30)$ & $30.9(38)$ & $55.0(33)$ & $70.8(84)$ & $67.7(184)$ & - & - & 51.1 (23) & - & - & $75.6(34)$ \\
\hline & $90+$ & $0.0(0)$ & $60.0(9)$ & $67.7(21)$ & $100.0(2)$ & $60.0(9)$ & $83.9(26)$ & - & - & - & - & - & - \\
\hline & & $* *$ & $* *$ & * & $* *$ & ** & ** & * & * & NS & NS & NS & . \\
\hline \multirow[t]{5}{*}{ South } & $70-74$ & $11.6(66)$ & - & - & $31.7(181)$ & - & - & $14.3(73)$ & - & - & $52.5(265)$ & - & - \\
\hline & $75-79$ & $20.4(52)$ & $13.6(50)$ & - & $38.8(99)$ & $30.7(113)$ & - & 23.8 (19) & $19.4(59)$ & - & $62.5(50)$ & $57.2(174)$ & - \\
\hline & $80-84$ & $30.9(29)$ & $24.4(39)$ & $21.7(51)$ & 45.7 (43) & $43.8(70)$ & $40.4(95)$ & - & 36.0 (18) & $22.9(41)$ & - & $70.0(35)$ & $68.5(122)$ \\
\hline & 85-89 & $42.9(9)$ & $43.2(16)$ & $36.7(44)$ & 71.4 (15) & $56.8(21)$ & $55.0(66)$ & - & - & 36.1 (22) & - & - & $77.0(47)$ \\
\hline & $90+$ & $0.0(0)$ & $75.0(3)$ & $45.0(9)$ & 100.0 (1) & $100.0(4)$ & 80.0 (16) & - & - & - & - & - & - \\
\hline
\end{tabular}

Figures are \% (N). Significance of trend, tested with $\chi^{2}$ test for linear trend: ${ }^{*} p<0.05 ;{ }^{* *} p<0.001$. 
Table 2 (B) Need for help in self care and mobility abilities per age group in men and women in north and south of Europe

\begin{tabular}{|c|c|c|c|c|c|c|c|c|c|c|c|c|c|}
\hline & \multirow[b]{4}{*}{$\begin{array}{l}\text { Age } \\
\text { group }\end{array}$} & \multicolumn{12}{|c|}{ Prevalence of need for help } \\
\hline & & \multicolumn{6}{|l|}{ Men } & \multicolumn{6}{|l|}{ Women } \\
\hline & & \multicolumn{3}{|l|}{ Self care } & \multicolumn{3}{|l|}{ Mobility } & \multicolumn{3}{|l|}{ Self care } & \multicolumn{3}{|l|}{ Mobility } \\
\hline & & 1988-1991 & 1993-1995 & 5 1998-2000 & 1988-1991 & 1993-1995 & 1998-2000 & $\begin{array}{l}1988- \\
1991\end{array}$ & 1993-1995 & $1998-2000$ & 1988-1991 & 1993-1995 & $1998-2000$ \\
\hline & & "* & ** & ** & ** & ** & NS & NS & NS & * & NS & * & NS \\
\hline \multirow{6}{*}{ North } & $70-74$ & $6.3(51)$ & - & - & $16.0(129)$ & - & - & $5.2(20)$ & - & - & $38.2(128)$ & - & - \\
\hline & $75-79$ & $11.1(44)$ & $8.0(41)$ & - & $21.8(86)$ & $21.6(111)$ & - & $9.2(7)$ & $13.5(30)$ & - & $43.4(33)$ & 37.8 (84) & - \\
\hline & $80-84$ & $14.4(24)$ & 9.0 (19) & $13.9(36)$ & $27.5(46)$ & $24.3(51)$ & $29.3(76)$ & - & $17.6(5)$ & $18.2(20)$ & - & $61.8(21)$ & 72.5 (79) \\
\hline & $85-89$ & 26.7 (16) & 21.3 (19) & 10.6 (13) & $41.7(25)$ & $47.2(42)$ & $40.3(50)$ & - & - & 35.6 (16) & - & - & 77.8 (35) \\
\hline & $90+$ & $0.0(0)$ & $33.3(5)$ & 41.9 (13) & $0.0(0)$ & $53.3(8)$ & $61.3(19)$ & - & - & - & - & - & - \\
\hline & & ** & ** & ** & ** & ** & ** & NS & NS & NS & * & NS & NS \\
\hline \multirow[t]{5}{*}{ South } & $70-74$ & $4.0(23)$ & - & - & $10.0(57)$ & - & - & $4.4(22)$ & - & - & $33.7(170)$ & - & - \\
\hline & $75-79$ & $9.8(25)$ & $7.6(28)$ & - & 16.5 (42) & $12.8(47)$ & - & $6.3(5)$ & $5.9(18)$ & - & $41.3(33)$ & $35.5(108)$ & - \\
\hline & $80-84$ & $25.5(24)$ & $15.0(24)$ & $13.6(32)$ & $29.8(28)$ & $23.8(89)$ & $20.4(48)$ & - & $10.0(5)$ & $12.8(23)$ & - & $52.0(26)$ & $47.8(85)$ \\
\hline & $85-89$ & $28.6(6)$ & 35.1 (13) & $29.2(35)$ & 52.4 (11) & 37.8 (14) & 42.5 (51) & - & - & 19.7 (12) & - & - & $67.2(41)$ \\
\hline & $90+$ & $0.0(0)$ & 75.0 (3) & $40.0(8)$ & $0.0(0)$ & $100.0(4)$ & $60.0(12)$ & - & - & - & - & - & - \\
\hline
\end{tabular}

Odds ratios and confidence intervals derived from logistic regression models are shown for disability in table $3 \mathrm{~A}$ and for need for help in 3B. The association of age with disability and need for help was curvilinear and seemed stronger in men than in women. Region showed some association with the outcome measures in favour of the south. The effect of region was independent of age and study in mobility activities in both sexes and in self care abilities in women in the longitudinal model.

Viewed from a time series perspective, the figures in tables $2 \mathrm{~A}$ and $2 \mathrm{~B}$ suggest a beneficial trend towards better functioning in similar age groups over time. Within similar age groups, proportions of subject with disability and need for help tend to be lower in the follow up surveys than at baseline, especially in the south (table 2A, B). In the longitudinal GEE analysis the beneficial trend over time remained significant in self care disability (OR 0.85, 95\% CI 0.75 to 0.97 in men and OR $0.64,95 \%$ CI 0.43 to 0.97 in women) and self care need for help (OR $0.82,95 \%$ CI 0.70 to 0.96 in men) even when age, study and region were controlled for. We also found a statistically significant interaction between region and follow up in mobility disability in men and self care disability in women (results not shown). Thus, among men the age and study adjusted prevalence of mobility disability decreased more in the south than in the north during the follow up. Among women, the same was true for self care disability. Adjusted for age, region, and follow up women had higher prevalence of disability in both domains and in need for help in mobility abilities ( $p$ values $0.001,<0.001$, and $<0.001$, respectively in GEE analysis, results not shown) when compared with men.

\section{DISCUSSION}

This 10 year longitudinal study shows that in the course of the 1990s physical functioning of European men and women aged $70+$ at baseline declined with age especially among men but ameliorated in succeeding birth cohorts over time. When age, study, and region were controlled for, this beneficial trend remained statistically significant in self care disability in both sexes and in self care need for help in men. Between

\begin{tabular}{|c|c|c|c|}
\hline & GEE Ic & ession analyses & \\
\hline \multirow{2}{*}{\multicolumn{4}{|c|}{ Self care }} \\
\hline & & & \\
\hline Age & 0.71 & $(0.50$ to 1.00$)$ & 0.048 \\
\hline $\mathrm{Age}^{2}$ & 1.00 & $(1.00$ to 1.01$)$ & 0.007 \\
\hline Region & 0.93 & $(0.78$ to 1.12$)$ & 0.459 \\
\hline Study & 1.06 & $(0.86$ to 1.31$)$ & 0.577 \\
\hline Follow up & 0.87 & $(0.77$ to 1.00$)$ & 0.048 \\
\hline \multicolumn{4}{|l|}{ Mobility } \\
\hline Age & 0.58 & $(0.42$ to 0.79$)$ & 0.001 \\
\hline $\mathrm{Age}^{2}$ & 1.00 & $(1.00$ to 1.01$)$ & $<0.001$ \\
\hline Region & 0.75 & $(0.64$ to 0.87$)$ & $<0.001$ \\
\hline Study & 0.85 & $(0.71$ to 1.00$)$ & 0.053 \\
\hline Follow up & 0.98 & $(0.87$ to 1.10$)$ & 0.707 \\
\hline \multicolumn{4}{|l|}{ Women } \\
\hline Age & 1.33 & $(0.65$ to 2.73$)$ & 0.440 \\
\hline $\mathrm{Age}^{2}$ & 1.00 & $(0.99$ to 1.00$)$ & 0.783 \\
\hline Region & 0.75 & $(0.58$ to 0.97$)$ & 0.031 \\
\hline Follow up & 0.64 & $(0.43$ to 0.96$)$ & 0.031 \\
\hline \multicolumn{4}{|l|}{ Mobility } \\
\hline Age & 0.64 & $(0.34$ to 1.19 ) & 0.160 \\
\hline $\mathrm{Age}^{2}$ & 1.00 & $(1.00$ to 1.01$)$ & 0.093 \\
\hline Region & 0.66 & (0.53 to 0.83 ) & $<0.001$ \\
\hline Follow up & 0.96 & $(0.67$ to 1.36$)$ & 0.812 \\
\hline
\end{tabular}




\begin{tabular}{|c|c|c|c|}
\hline & \multicolumn{3}{|c|}{ GEE logistic regression analyses } \\
\hline & OR & $95 \% \mathrm{Cl}$ & p Value \\
\hline \multicolumn{4}{|l|}{ Men } \\
\hline \multicolumn{4}{|l|}{ Self care } \\
\hline Age & 1.03 & $(0.67$ to 1.58$)$ & 0.894 \\
\hline $\mathrm{Age}^{2}$ & 1.00 & $(0.99$ to 1.00$)$ & 0.590 \\
\hline Region & 1.15 & $(0.93$ to 1.43$)$ & 0.200 \\
\hline Study & 0.95 & $(0.93$ to 1.43$)$ & 0.694 \\
\hline Follow up & 0.83 & $(0.71$ to 0.97$)$ & 0.023 \\
\hline \multicolumn{4}{|l|}{ Mobility } \\
\hline Age & 0.66 & $(0.47$ to 0.94$)$ & 0.021 \\
\hline $\mathrm{Age}^{2}$ & 1.00 & $(1.00$ to 1.01$)$ & 0.002 \\
\hline Region & 0.69 & $(0.58$ to 0.83$)$ & $<0.001$ \\
\hline Study & 0.80 & $(0.66$ to 0.98$)$ & 0.033 \\
\hline Follow up & 0.95 & $(0.83$ to 1.08$)$ & 0.441 \\
\hline \multicolumn{4}{|l|}{$\begin{array}{l}\text { Women } \\
\text { Self care }\end{array}$} \\
\hline Age & 1.82 & $(0.60$ to 5.53$)$ & 0.293 \\
\hline $\mathrm{Age}^{2}$ & 1.00 & $(0.99$ to 1.01$)$ & 0.484 \\
\hline Region & 0.60 & $(0.43$ to 0.85$)$ & 0.003 \\
\hline Follow up & 0.70 & $(0.40$ to 1.22$)$ & 0.205 \\
\hline \multicolumn{4}{|l|}{ Mobility } \\
\hline Age & 0.79 & $(0.42$ to 1.46$)$ & 0.445 \\
\hline $\mathrm{Age}^{2}$ & 1.00 & $(1.00$ to 1.01$)$ & 0.252 \\
\hline Region & 0.50 & $(0.40$ to 0.62$)$ & $<0.001$ \\
\hline Follow up & 0.93 & $(0.66$ to 1.32$)$ & 0.684 \\
\hline
\end{tabular}

the two geographical regions we found differences showing a more favourable time trend in the south than in the north of Europe.

Some potential confounders should be kept in mind when interpreting the results. Selective drop out attributable to death must always be taken into account when interpreting health changes in the elderly population. However, this is more likely to have levelled off the age effect than to have emphasised it. On the other hand, the main purpose of this paper was to study the trends of disability at population level among the surviving elderly population.

Poor physical functioning is predictive of non-response. ${ }^{17}$ Subjects who participated in the surveys may thus have been healthier and more active than those who did not ${ }^{18}$ but it is difficult to evaluate the magnitude of the impact of low response rates on the time related changes seen in this study. With comparatively high follow up response rates this is unlikely to have biased the results. Because of low initial participation rates in some centres, this issue is especially relevant in SENECA data. The most common reasons reported for baseline non-participation in SENECA were no time/interest to participate and illness ( $75 \%$ and $12 \%$ of nonparticipants, respectively). ${ }^{19}$

Confounding attributable to unknown cultural (that is, culturally defined norms), life circumstantial or socioeconomic factors, or factors such as type and availability of care for the elderly is possible but it is difficult to estimate to what extent they may have affected the results. Changes in socioeconomic conditions and availability of care may follow different patterns in different countries. Not accounting for these factors in this study may have affected the point estimates of the impact of age and follow up on functioning but it is unlikely that it has biased the trends seen in our study. The countries participating in the HALE study have experienced quite similar demographic changes with respect to the average life expectancy at the age of 60 . Between years 1991 and 1998, the mean number of years still to be lived by a person who has reached 60 increased by 0.6 (Denmark)-1.2 (Finland, Portugal) years in men and by 0.2 (Denmark)-1.2
(Portugal, France) years in women to 18.4 (Denmark)-20.4 (Switzerland) years in men and to 21.9(Denmark)-25.2 (France) years in women. ${ }^{20}$

Self reporting is another possible source of bias. In the oldold, self reported measures may give a more optimistic view of the physical abilities than performance based measures. ${ }^{21}$ Some studies have shown a strong correlation between subjective and objective measures of physical functioning ${ }^{22}$ whereas others have found the association to be much lower. ${ }^{15}$ However, subjective and objective measures capture physical abilities differently: the performance indices may be seen as indicators of functional limitations at a given time point whereas self reported ADL reflects experienced disability over at least a slightly longer period of time and, thus, the ability of a person to live independently in their own home, whether relying on various aids or equipment or without any aid.

In this study significant confounding attributable to methodological differences (definitions and wording of questions, translation of the questionnaires) is unlikely because we assessed physical functioning by means of a standardised questionnaire and only ADL items identical in both studies were included in the analyses. Furthermore, the

\section{What this study adds}

- This longitudinal population study is the first to show that physical functioning of elderly Europeans has ameliorated over time in succeeding birth cohorts.

- While absolute numbers of elderly people are increasing, proportions of elderly people with disability may decrease over time.

- Our findings imply that disability prevalence trends may differ between populations.

- Future research should focus on identifying modifiable factors that play a part in dynamics of functioning. 
translation processes were performed in a similar way in both studies. We also used multivariate models to adjust for study (FINE compared with SENECA) to avoid bias attributable to differences between the two study populations.

Older adults' physical functioning may either decline or improve over time. ${ }^{10} 23$ Therefore, we used a statistical method that accounts for changes in both directions within and between subjects. To our knowledge, ours is the first study to report on disability prevalence trends in aged Europeans in a longitudinal setting. Previous comparative cross national studies have been cross sectional. ${ }^{24} 25$

Our finding is in line with existing longitudinal studies based on national samples. A prospective study in a younger population of Finnish men and women showed results congruent with those of ours. ' This study measured self reported functioning in mobility tasks and found gradual improvement in functioning with succeeding birth cohorts. Another Finnish population study ${ }^{26}$ failed to find a significant cohort effect in a population of men and women aged $75+$ although the general trend was towards slightly better functioning in later birth cohorts. A secular trend toward a less disabled and healthier population has also been reported in US populations aged $65+$ by Manton et $a l^{27}$ and 55 to 70 years by Allaire et al. ${ }^{28}$ Manton et al further showed that the reduction in disability over time, which had already been seen a decade earlier, had accelerated from the 1980s to the 1990s.

Interestingly, a Canadian study based on earlier samples reported contradicting results suggesting that later generations were less healthy than earlier ones. ${ }^{29}$ It is possible that populations experience a shift toward healthier aging at different phase and at different points in time. Furthermore, it has been suggested that as a country becomes more developed there may be an increase in the prevalence of disability among the elderly population. ${ }^{25}$ It is a limitation of this study that the economic development of the participating countries could not be assessed.

The finding that physical functioning of elderly Europeans has improved over time is important from the perspective of health policy making. It implies that the need for social and medical services may not increase in phase with aging of the populations. European countries will experience an increase in absolute numbers of elderly people and thus also the absolute numbers of people with functional impairment and disability are likely to increase. However, as later birth cohorts maintain functional abilities better than earlier ones, the proportions of older people with disability will decrease.

In view of earlier studies we suggest that culturally determined lifestyle related or socioeconomic factors may explain the regional variation in disability prevalence trends seen in this study. The importance of socioeconomic inequalities in health that exist also among older adults ${ }^{30}$ has been shown to vary between cultures ${ }^{31}$ and socioeconomic groups may adopt health related practices ${ }^{32}$ differently. Health related lifestyle and health behaviour are also affected by cultural traditions. Healthy lifestyle in general has been shown to delay age related deterioration of health. ${ }^{11}$

\section{Policy implications}

As European populations are aging, the proportions of elderly people that remain active and independent may increase. Thus, the costs of population aging for public health and medical systems may not be as high as has been previously assumed. Resources should be targeted toward promoting physical functioning in later life.
While the relation between age and chronic disease with functional impairment is well reported, comparatively little is known about the role of other possibly modifiable factors in dynamics of functioning. Existing data have proved that comparatively high proportions of elderly people maintain their functional capacity or even experience recovery of impaired functioning. ${ }^{23}$ Policy makers and health professionals need concrete tools when planning actions aimed at preventing or reverting functional decline both at population and individual level. Future research should therefore focus on identifying factors that help promote physical functioning in older adults.

\section{ACKNOWLEDGEMENTS}

This study is based on data of the HALE project (healthy ageing: longitudinal study in Europe) and supported by a grant from the European Union (QLK6-CT-2000-00211) to D Kromhout. The following principal investigators contributed to the HALE project: Belgium Prof G de Backer,, University of Ghent, Ghent; Denmark Prof M Schroll, Bispebjerk Hospital, Copenhagen; Finland Prof A Nissinen, National Public Health Institute, Helsinki; France Dr M Ferry, Centre Hospitalier de Valence, Valence, Prof J L Schlienger, Université Louis Pasteur, Strasbourg; Greece Prof A Kafatos, University of Crete, Iraklion, Crete; Hungary Dr G Zajkas, József Fodor National Centre For Public Health, National Institute of Food Hygiene and Nutrition, Budapest; Italy Prof G Enzi, Università degli Study di Padova, Padova; Prof F Fidanza, Perugia; Dr S Giampaoli, Istituto Superiore di Sanità, Rome; Dr G Maiani, Istituto Nazionale di Ricerca per gli Alimenti e la Nutrizione, Rome; Prof A Menotti, Associazione per la Ricerca Cardiologica, Rome; Netherlands Dr L de Groot, Wageningen University, Wageningen; Prof D Kromhout, National Institute for Public Health and the Environment, Bilthoven; Prof W van Staveren, Wageningen University, Wageningen; Dr M Tijhuis, National Institute for Public Health and the Environment, Bilthoven; Poland Prof A Brzozowska, Warsaw Agricultural University, Warsaw; Portugal Prof J A Amorim Cruz, Instituto Nacional de Saude, Lisbon; Spain Prof O Moreiras-Varela, Universidad Complutense de Madrid, Madrid; Switzerland Dr D Schlettwein-Gsell, Basle.

\section{Authors' affiliations}

S Äijänseppä, I-L Notkola, A Nissinen, National Public Health Institute, Helsinki, Finland

M Tijhuis, D Kromhout, National Institute for Public Health and the Environment, Bilthoven, Netherlands

W van Staveren, Wageningen University and Research Centre, Wageningen, Netherlands

Funding: none

Conflicts of interest: none declared.

\section{APPENDIX 1}

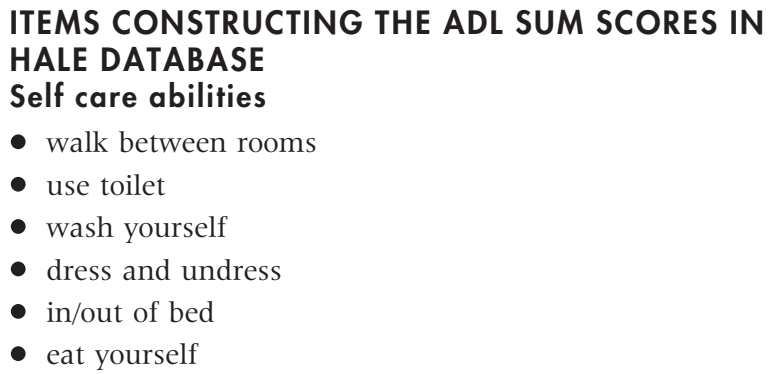

ITEMS CONSTRUCTING THE ADL SUM SCORES IN HALE DATABASE

care abilities

- use toilet

wash yourself

- in/out of bed

- eat yourself
Mobility abilities
- move outdoors
- use stairs
- walk 400 metres
- carry $5 \mathrm{~kg}$ 


\section{REFERENCES}

1 Fries JF. Medical perspectives upon successful ageing. In: Baltes PB, Baltes MM eds. Successful ageing, perspectives from the behavioral sciences. Cambridge: Cambridge University Press, 1993:35-49.

2 Scott WK, Macera CA, Cornman CB, et al. Functional health status as a predictor of mortality in men and women over 65. J Clin Epidemiol 1997:50:291-6.

3 Ganguli M, Dodge $\mathrm{HH}$, Mulsant $\mathrm{BH}$. Rates and predictors of mortality in an ageing, rural, community-based cohort: the role of depression. Arch Gen Psychiatry 2002;59:1046-52.

4 Korten $A E$, Jorm AF, Jiao $Z$, et al. Health, cognitive, and psychosocial factors as predictors of mortality in an elderly community sample. J Epidemiol Community Health 1999;53:83-8.

5 Bernard SL, Kincade JE, Konrad TR, et al. Predicting mortality from community surveys of older adults: the importance of self-rated functional ability. J Gerontol B Psychol Sci Soc Sci 1997:52(suppl):S155-63.

6 Melzer D, McWilliams B, Brayne C, et al. Profile of disability in elderly people: estimates from a longitudinal population study. BMJ 1999;318:1108-11.

7 Fried LP, Guralnik JM. Disability in older adults: evidence regarding significance, etiology, and risk. J Am Geriatr Soc 1997;45:92-100.

8 Femia EE, Zarit SH, Johansson B. Predicting change in activities of daily living: a longitudinal study of the oldest old in Sweden.J Gerontol B Psychol Sci Soc Sci 1997;52(suppl):P294-302.

9 Malmberg JJ, Miilunpalo SI, Vuori IM, et al. Improved functional status in 16 years of follow up of middle aged and elderly men and women in north eastern Finland. J Epidemiol Community Health 2002;56:905-12.

10 Beland F, Zunzunegui MV. Predictors of functional status in older people living at home. Age Ageing 1999;28:153-9.

11 Haveman-Nies A, de Groot LCPGM, van Staveren WA. Dietary quality, lifestyle factors and healthy ageing in Europe: the SENECA study. Age Ageing 2003:32:427-34.

12 Schroll Bjornsbo K, Ferry M, de Groot CP, et al. Changes in physical performance in elderly Europeans. SENECA 1993-1999. J Nutr Health Ageing 2002;6:9-14.

13 Nissinen A, Tervahauta M, Pekkanen J, et al. Prevalence and change of cardiovascular risk factors among men born 1900-19: the Finnish cohorts of the seven countries study. Age Ageing 1993;22:365-76.

14 Heikkinen E, Waters WE, Brezinski Z. The elderly in eleven countries: a sociomedical survey. Public health in Europe 21. Copenhagen: WHO, 1983.

15 Hoeymans N, Feskens EJ, van den Bos GA, et al. Measuring functional status: cross-sectional and longitudinal associations between performance and selfreport (Zutphen elderly study 1990-1993). J Clin Epidemiol 1996:49:1103-10.

16 Rabe-Hesketh S, Everitt B. A handbook of statistical analyses using STATA. London: Chapman and Hall/CRC, 1999.
17 Hoeymans N, Feskens EJ, van den Bos GA, et al. Non-response bias in a study of cardiovascular diseases, functional status and self-rated health among elderly men. Age Ageing 1998;27:35-40

18 Van't Hof MA, Burema J. Assessment of bias in the SENECA study. Eur J Clin Nutr 1996;50(suppl 2):S4-8.

19 Van't Hof MA, Hautvast JG, Schroll M, et al. Design, methods and participation. Euronut SENECA investigators. Eur J Clin Nutr 1991;45(suppl 3):S5-22.

20 Eurostat reference database. Free data. Long term indicators. Life expectancy and mortality. http://europa.eu.int/newcronos/.

21 Sinoff G, Ore L. The Barthel activities of daily living index: self-reporting versus actual performance in the old-old ( $>$ or $=75$ years). J Am Geriatr Soc 1997;45:832-6.

22 Kivinen P, Sulkava R, Halonen P, et al. Self-reported and performance-based functional status and associated factors among elderly men: the Finnish cohorts of the seven countries study. J Clin Epidemiol 1998;51:1243-52.

23 Beckett LA, Brock DB, Lemke JH, et al. Analysis of change in self-reported physical function among older persons in four population studies. Am J Epidemiol 1996; 143:766-78.

24 Heslin JM, Soveri PJ, Winoy JB, et al. Health status and service utilisation of older people in different European countries. Scand J Prim Health Care 2001;19:218-22.

25 Lamb VL. A cross-national study of quality of life factors associated with patterns of elderly disablement. Soc Sci Med 1996:42:363-77.

26 Winblad I, Jaaskelainen M, Kivela SL, et al. Prevalence of disability in three birth cohorts at old age over time spans of 10 and 20 years. J Clin Epidemiol 2001;54:1019-24.

27 Huisman M, Kunst AE, Mackenbach JP. Socioeconomic inequalities in morbidity among the elderly; a European overview. Soc Sci Med 2003;57:861-73.

28 Manton KG, Gu Xiliang. Changes in the prevalence of chronic disability in the United States black and nonblack population above age 65 from 1982 to 1999. Proc Natl Acad Sci USA $2001 ; 98: 6354-9$.

29 Allaire SH, La Valley MT, Evans SR, et al. Evidence for decline in disability and improved health among persons aged 55 to 70 years: the Framingham health study. Am J Public Health 1999:89:1678-83.

30 Roos NP, Havens B, Black C. Living longer but doing worse: assessing health status in elderly persons at two points in time in Manitoba, Canada, 1971 and 1983. Soc Sci Med 1993;36:273-82.

31 Von dem Knesebeck O, Luschen G, Cockerham WC, et al. Socioeconomic status and health among the aged in the United States and Germany: a comparative cross-sectional study. Soc Sci Med 2003;57:1643-52.

32 Sulander T, Helakorpi S, Rahkonen $\mathrm{O}$, et al. Changes and associations in healthy diet among the Finnish elderly, 1985-2001. Age Ageing $2003 ; 32: 394-400$

\section{bmjupdates+}

bmjupdates+ is a unique and free alerting service, designed to keep you up to date with the medical literature that is truly important to your practice.

bmjupdates+ will alert you to important new research and will provide you with the best new evidence concerning important advances in health care, tailored to your medical interests and time demands.

Where does the information come from?

bmjupdates+ applies an expert critical appraisal filter to over 100 top medical journals A panel of over 2000 physicians find the few 'must read' studies for each area of clinical interest

Sign up to receive your tailored email alerts, searching access and more...

www.bmjupdates.com 